\title{
Elaboração de objetos de aprendizagem com o software GeoGebra para o ensino de geometria
}

Development of learning objects with the GeoGebra software for the teaching of geometry

\author{
Rafael Enrique Gutiérrez Araujo* \\ Vinícius Pazuch**
}

\section{Resumo}

Em geometria dinâmica, Objetos de Aprendizagem (OA) são recursos que podem colaborar na prática do professor que ensina matemática. Assim, o objetivo deste estudo foi o de descrever a elaboração de um OA utilizando o software GeoGebra para favorecer a exploração e a validação de propriedades geométricas estudadas nos Anos Finais do Ensino Fundamental. A elaboração desse OA fundamentou-se nas recomendações de documentos curriculares sobre congruência de triângulos e demonstraçõ̃es de propriedades de quadriláteros. Especificamente, o OA foi elaborado para apoiar o ensino da propriedade relacionada à congruência entre as diagonais de todo trapézio isósceles usando o critério de congruência Lado-Ângulo-Lado (LAL). A elaboração do OA envolveu três momentos: (i) a construção do trapézio e (ii) a criação e (iii) a programação da animação. Considera-se que a utilização de OA permite aos estudantes o desenvolvimento de processos de exploração, visualização e investigação de ideias e relações geométricas. Para tanto, indica-se aos professores o uso de tarefas que incluam OA. Salienta-se a importância de processos de formação continuada para a integração desse tipo de recurso digital no ensino da geometria.

Palavras-chave: Geometria Dinâmica. Validação. Construções geométricas. Anos Finais do Ensino Fundamental.

\section{Introdução}

Na geometria euclidiana, as construções geométricas são fundamentais na exploração e na validação de propriedades. Os Softwares de Geometria Dinâmica (SGD) são recursos com o potencial de contribuir para o processo de validação

\footnotetext{
* Licenciado em Educação Matemática e Física pela Universidade do Zulia, Mestrando em Ensino e História das Ciências e da Matemática da Universidade Federal do ABC, rafael.gutierrez0593@gmail.com

** Doutor em Ensino de Ciências e Matemática pela Universidade Luterana do Brasil, Professor do Centro de Matemática, Computação e Cognição (CMCC) da Universidade Federal do ABC, vinicius.pazuch@ufabc.edu.br
} 
de ideias e relações matemáticas com base na análise de construções geométricas no ensino da geometria nos Anos Finais do Ensino Fundamental.

Com relação aos Anos Finais do Fundamental, a Base Nacional Comum Curricular (BNCC) destaca a importância do ensino de geometria e da utilização de tecnologias digitais (BRASIL, 2017). Notadamente, a BNCC sinaliza que "[...] devem ser enfatizadas também as tarefas que analisam e produzem transformações e ampliações/reduções de figuras geométricas planas [...]" (BRASIL, 2017, p. 270). Além disso, para esse nível de ensino, o documento curricular destaca que é necessário que os estudantes "[...] sejam capazes de reconhecer as condições necessárias e suficientes para obter triângulos congruentes ou semelhantes e que saibam aplicar esse conhecimento para realizar demonstrações simples [...]" (BRASIL, 2017, p. 270). Entende-se que as demonstrações simples implicam o tratamento de processos de validação, o que faz sentido aos professores e aos estudantes na Educação Básica (NACARATO; GOMES; GRANDO, 2008).

Nesse sentido, é relevante pontuar que as tarefas elaboradas pelos professores precisam contemplar diferentes recursos didáticos e digitais. Um dos recursos citados pela BNCC são os SGD. Segundo a BNCC "[...] esses recursos e materiais precisam estar integrados a situações que propiciem a reflexão, contribuindo para a sistematização e a formalização dos conceitos matemáticos" (BRASIL, 2017, p. 296).

Buscando refletir sobre tarefas para pensar não somente a aprendizagem dos estudantes como também a prática do professor que ensina matemática nos Anos Finais do Ensino Fundamental e que deseja integrar SGD, apresenta-se esse artigo. $O$ objetivo central foi o de descrever a elaboração de um objeto de aprendizagem utilizando o software GeoGebra para favorecer a exploração e a validação de propriedades geométricas estudadas nos Anos Finais do Ensino Fundamental. O GeoGebra ${ }^{1}$ é um software de matemática dinâmica que oferece um ambiente de geometria dinâmica, entre outras aplicações (HOHENWARTER;

\footnotetext{
1 Optou-se pelo uso da palavra "GeoGebra" em vez de "software GeoGebra".
} 
HOHENWARTER; LAVICZA, 2009). Este atributo faz dele um software ideal para elaborar OA de conteúdos matemáticos.

Para atingir esse objetivo, considera-se as sugestões presentes na BNCC. Foi elaborado um OA sobre o objeto de conhecimento "Congruência de triângulos e demonstrações de propriedades de quadriláteros" (BRASIL, 2017, p. 312). O OA foi constituído com a perspectiva de desenvolver a seguinte habilidade nos estudantes do Ensino Fundamental: "Demonstrar propriedades de quadriláteros por meio da identificação da congruência de triângulos" (BRASIL, 2017, p. 313).

A seguir são apresentados os SGD como meios para a exploração e a validação de ideias e relações matemáticas. Em seguida são discutidas as compreensões sobre objetos de aprendizagem. Logo após, detalha-se a descrição do OA com o GeoGebra. Por fim, nas considerações finais, são destacadas as reflexões que o professor que ensina matemática pode adotar em sua prática pedagógica.

\section{Softwares de geometria dinâmica como meios para a validação de ideias matemáticas}

Pesquisas em Educação Matemática têm abordado a temática do ensino de prova e/ou demonstração a partir do uso de SGD (HOYLES; JONES, 1998; HANNA, 2000; SCHER, 2005; STYLIANIDES; STYLIANIDES, 2005; OLIVERO; ROBUTTI, 2007; SINCLAIR; YURITA, 2008; POWELL, 2014).

A literatura especializada aborda quatro aspectos teóricos em geometria dinâmica, que são a exploração, a validação, o uso de medidas e a mudança de discurso. Essas noções teóricas podem favorecer o ensino de prova e/ou demonstração de conceitos geométricos. O OA elaborado e descrito neste artigo vincula-se a essas noções.

Para Hoyles e Jones (1998) o uso de um SGD permite criar e explorar objetos básicos como pontos, retas e circunferências. Esses recursos tecnológicos fornecem o modelo da geometria euclidiana, apresentando feedback por meio do ato de arrastar para descobrir se as construções ou teoremas estão 
"corretos" (HOYLES; JONES, 1998). A ação de "arrastar" (ou "teste do arrastar") é entendida como fator constituinte da geometria dinâmica. O seu uso permite que ideias e relações matemáticas sejam exploradas e visualizadas em conceitos geométricos.

Uma construção geométrica realizada com SGD "[...] pode proporcionar uma oportunidade para alguns estudantes considerar o 'porquê...', além do 'o que se' e o 'que se não..." (HOYLES; JONES, 1998, p.123, tradução nossa). Segundo os autores, essa oportunidade é gerada mediante a elaboração de tarefas de geometria dinâmica em conexão com duas questões. A primeira questão envolve a garantia de que os estudantes trabalhem com aspectos geométricos verdadeiros em geometria euclidiana; a segunda estipula que as experiências dos estudantes permitam-lhes explicar que esses fatos geométricos são verdadeiros (HOYLES; JONES, 1998).

As duas questões estão atreladas à exploração de conceitos geométricos com o uso de SGD e à explicação de que esses aspectos são verdadeiros segundo a geometria euclidiana. Hanna (2000) discute a exploração, a heurística e a visualização como noções teóricas que podem contribuir para o ensino de uma prova e/ou demonstração.

Segundo Hanna (2000, p.12, tradução nossa), "O software de geometria dinâmica tem o potencial de provocar a exploração e a prova ao mesmo tempo". Além disso, "Os estudantes podem também facilmente testar conjecturas por meio da exploração das propriedades dadas pelas construções que eles têm produzido ou mesmo 'descobrir' novas propriedades" (HANNA, 2000, p.12, tradução nossa). Um exemplo é apresentado a seguir.

Hanna (2000) traz um exemplo sobre as potencialidades do SGD para questionar a necessidade de prova analítica. Imagina-se que um estudante quer "provar" o teorema que declara que, em um triângulo $A B C$, mediatrizes se cruzam em um único ponto. $O$ estudante poderia construir, com régua e compasso, um triângulo com as três mediatrizes e mostrar que o teorema é verdadeiro. A geometria dinâmica tem uma vantagem importante. O software possibilita que o 
estudante escolha um ponto do triângulo $A B C$ e 0 arraste sobre a tela, de tal maneira que a sua forma geométrica seja alterada sem que as mediatrizes fiquem redesenhadas equivocadamente. Isso mostra ao estudante que as três mediatrizes ainda se cruzam em um único ponto $O$, chamado de circuncentro do triângulo $A B C$, independentemente da forma do triângulo (Figura 1).

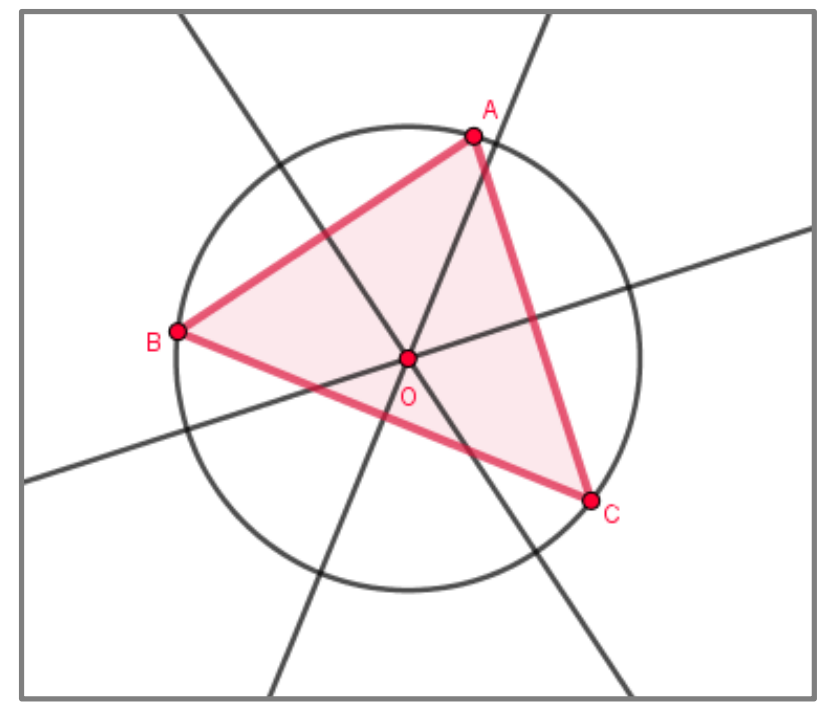

Figura 1 - Circuncentro de um triângulo Fonte: Adaptado de Hanna (2000).

A partir do exemplo dado entende-se que os SGD "[...] proporcionam ao estudante uma forte evidência de que o teorema é verdadeiro (e reforçam o valor da exploração, em geral, dando aos estudantes a confiança em um teorema)" (HANNA, 2000, p.13, tradução nossa). Logo, a exploração, a primeira noção teórica investigada, não é uma questão nova, mas uma noção importante no processo de demonstração perceptível antes mesmo da invenção dos computadores. Entende-se que a exploração com SGD é uma noção que contribui para a realização de provas e/ou demonstrações.

A segunda noção teórica que auxilia na demonstração é a validação. A geometria euclidiana clássica considera o uso de papel e lápis para a solução de uma tarefa envolvendo construção geométrica. $O$ critério de validação desta solução exige que ela tenha sido construída usando apenas régua e compasso. 
Em geometria dinâmica, o critério de validação em uma construção geométrica é válido se, e somente se, esta mantém as propriedades que a constituem durante o teste do arrastar (STYLIANIDES; STYLIANIDES, 2005). A aceitação do "arrastar" (nas vezes de indicador de validação das soluções geométricas) como ação necessária e suficiente suporta uma inconsistência no conjunto de figuras construídas. Essa inconsistência se dá entre a geometria incorporada em SGD e a geometria euclidiana clássica (STYLIANIDES; STYLIANIDES, 2005). Para os referidos autores,

[...] o teste do arrastar pode permitir a validade das construções criadas usando instrumentos de medição (tais como medidas de ângulo, cálculos e rotações usando ângulos numericamente especificados). Tais construções, no entanto, são incompatíveis com a geometria clássica, em que os únicos instrumentos permitidos são a régua e o compasso (STYLIANIDES; STYLIANIDES, 2005, p. 32, tradução nossa).

Diante disso são apresentados dois critérios de validação de soluções de construções geométricas em SGD (STYLIANIDES; STYLIANIDES, 2005). O primeiro, denominado critério do teste de arrastar, revela que a solução de uma construção geométrica realizada em um ambiente de geometria dinâmica é válida se, e somente se, a construção final mantiver suas propriedades geométricas durante a ação de arrastar. O segundo critério, chamado de critério de compatibilidade, abrange o primeiro critério, e o processo de construção geométrica não pode violar as restrições de construção em um ambiente de geometria dinâmica (STYLIANIDES; STYLIANIDES, 2005).

Scher (2005) argumenta que, para avaliar se um quadrilátero desenhado em um caderno é um quadrado, basta medir seus lados e ângulos: "Se os lados são iguais e os ângulos medem 90으, o quadrilátero é um quadrado" (SCHER, 2005, p.115, tradução nossa). Se o quadrilátero é interativo e não foi construído a partir das propriedades que constituem essa figura geométrica, mesmo delimitando-se as medidas pelo SGD, tal quadrilátero não se configura como um quadrado. Essa constatação é ilustrada pela Figura 2, na qual há deformação do quadrado após o teste de arrastar. 


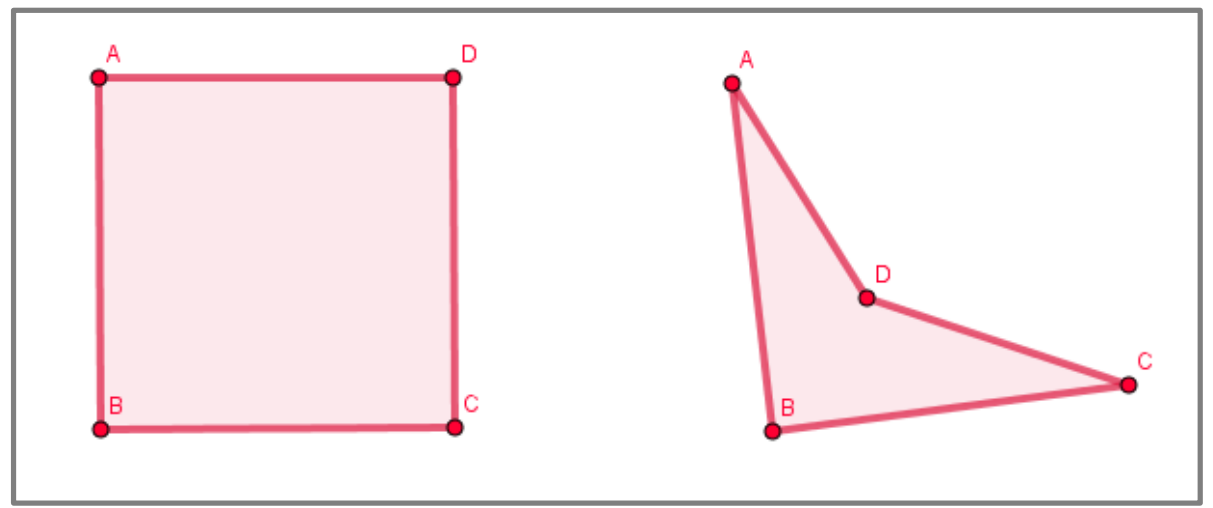

Figura 2. Construção de um quadrado - Adaptado de Scher (2005).

Fonte: "ABCD parece um quadrado, mas ele não é" (SCHER, 2005, p.116, tradução nossa)

Em relação ao processo de validação de construções geométricas com SGD, Stylianides e Stylianides (2005) apontam para a importância dos instrumentos de medição que esses recursos tecnológicos disponibilizam (ângulo, área, perímetro, distância entre dois pontos). Paralelo a isso, Olivero e Robutti (2007) destacam o uso de medidas, a terceira noção teórica investigada, como ferramentas para a formulação de ideias e de relações matemáticas que podem contribuir para provas e/ou demonstrações.

Salienta-se que essas modalidades podem ser observadas na mesma situação ou de forma específica (como na Figura 2). O uso de medidas pode contribuir com os processos de exploração e de validação de ideias matemáticas por meio da utilização de SGD na elaboração de OA para o ensino de geometria.

A quarta noção teórica é a mudança de discurso matemático (SINCLAIR; YURITA, 2008) na exploração e na validação das construções geométricas realizadas com o uso de SGD. Em particular, entende-se que a imagem dinâmica gera uma percepção visual distinta (HANNA, 2000).

Nesse sentido, Sinclair e Yurita (2008) comparam um quadrado desenhado no quadro-negro com um quadrado construído com o uso de SGD, explicitando que esses podem diferir tanto na forma como foram feitos como na forma como podem ser tratados em termos conceituais. $O$ avanço em termos de discurso matemático se refere à incorporação de novas palavras (arrastar, movimentar, 
animar) à exploração e à validação de ideias e de relações matemáticas em geometria dinâmica.

Em particular, na geometria dinâmica, o modo em que o professor pensa figuras geométricas difere daquele em relação às figuras estáticas. Essa mudança de discurso gera narrativas necessárias ou assumidas pela geometria dinâmica, nas quais professores e estudantes podem contribuir na legitimação da geometria dinâmica, seja em seus próprios termos, seja em relação à geometria estática (SINCLAIR; YURITA, 2008).

Em síntese, esta seção discutiu brevemente quatro noções teóricas sobre construções geométricas com SGD: a exploração, a validação, o uso de medidas e a mudança no discurso matemático. Compreende-se que tais noções teóricas podem sustentar ideias e relações matemáticas necessárias para a realização de provas e/ou demonstrações no ensino de geometria. A próxima seção descreve os aspectos teóricos dos OA.

\section{Objetos de aprendizagem}

As definições de OA vigentes no campo educativo são variadas. Por um lado, Koper (2003) os define como recursos virtuais utilizados em contextos de ensino para contribuir com a aprendizagem e disponíveis a outros professores para uso em suas aulas. Por outro lado, Santos (2007) define um OA como qualquer material digital que ofereça informações para a construção de conhecimento, independentemente de essas informações estarem em forma de imagem, página HTML, animação ou simulação. Neste artigo um OA é considerado um recurso virtual passível de ser usado e reutilizado em apoio à aprendizagem mediante atividades interativas como animações ou simulações (KALINKE et al., 2015).

A literatura especializada traz uma diversidade de características destes objetos. Assim, Sabbatini (2012) distingue um OA dos demais recursos didáticos com base nas seguintes características: 
- Reutilização, isto é, a capacidade de serem usados em diferentes contextos de ensino com outras atividades e desafios;

- Portabilidade, ou a possibilidade de usá-los em diferentes plataformas técnicas;

- Modularidade, ou seja, a maneira em que contêm ou estão contidos em outros objetos, dando lugar à ideia de combinação;

- Autossuficiência, fator que diz respeito ao fato de não dependerem de outros objetos para trazerem sentido ao ensino;

- Descrição, sinônimo da capacidade de serem descritos com base em metadados, como autor, palavras-chave, idioma, entre outros.

Audino e Nascimento (2010) ressaltam outras características dos OA, as quais se referem às possibilidades de:

- Acessá-los em qualquer lugar;

- Explorar sua interatividade;

- Transportá-los em diversas mídias, como pen-drives e CDs, por exemplo. Em particular, Kalinke et al. (2015) reportam as seguintes características fundamentais dos OA:

- O tamanho reduzido, no sentido de que podem ser usados no tempo de uma ou duas aulas;

- A facilidade de uso, a qual permite que o estudante dedique a maior parte de sua atenção às questões que deseja aprender;

- A expectativa de aprendizagem, a qual deve ser intermediada por um OA em sala de aula (daí o nome objeto de "aprendizagem").

Portanto, um recurso digital que apresente todas as características elencadas sem trazer consigo um propósito pedagógico não pode ser considerado como OA. Além de suas características, os OA apresentam uma variedade de vantagens que podem ajudar os estudantes a estabelecerem uma relação mais afetiva e dinâmica com os conceitos a serem aprendidos. Em relação a isso, Gallo e Pinto (2010) destacam que OA permitem aos estudantes, entre outras coisas, criar e comprovar hipóteses, relacionar conceitos, resolver 
problemas e fazer descobertas por meio de situações de exploração e investigação. Do mesmo modo, Kalinke et al. (2015) afirmam que os OA permitem aos estudantes explorar dinamicamente os conteúdos, estabelecer as conexões entre as diferentes formas de representação de um conceito e investigar as conexões entre os conceitos matemáticos e as situações cotidianas. Na próxima seção é descrita a elaboração de um OA para o ensino de geometria.

\section{Elaboração do objeto de aprendizagem com o GeoGebra}

Esta seção descreve a elaboração do OA na forma de uma animação com o GeoGebra, o qual está disponível em < https://www.geogebra.org/m/ucrncm4a >. Esse OA foi desenvolvido como forma de contribuir com o ensino da seguinte propriedade geométrica: "as diagonais de todo trapézio isósceles têm a mesma medida". Para validar essa propriedade, decidiu-se utilizar o critério de congruência Lado-Ângulo-Lado (LAL), o qual estabelece que dois triângulos são congruentes se estes compartilham dois lados de igual medida assim e o ângulo formado por esses lados congruentes. A descrição da elaboração da animação se organiza em três subseções, que são (i) a construção do quadrilátero em questão e (ii) a criação e a (iii) programação da animação.

\subsection{Construção do trapézio}

O GeoGebra não dispõe de uma ferramenta específica para construir trapézios ou qualquer tipo de quadrilátero em particular. No entanto, o software dispõe da ferramenta "Polígono", a qual permite construir qualquer polígono a partir dos seus vértices. Uma vez que o objeto pretendido foi um quadrilátero, foi necessário localizar os quatro vértices do trapézio isósceles segundo um processo de construção geométrica e, portanto, usar a ferramenta mencionada para a finalização da sua construção.

Para iniciar a construção do trapézio localizaram-se seus dois primeiros vértices, $A$ e $B$, com a ferramenta "Ponto" clicando em qualquer zona da "Janela de Visualização". Esses vértices são os extremos da base maior do trapézio. Para facilitar a elaboração da animação, decidiu-se que a medida dos ângulos 
contíguos à base maior do trapézio fosse igual a $60^{\circ}$, para a qual a ferramenta "Ângulo com Amplitude Fixa" foi usada. Esta aplica uma rotação de um ponto em relação a outro, em uma amplitude específica. Ao rotacionar o vértice $A$ em relação a $B$ com uma amplitude de $60^{\circ}$, em sentido horário e vice-versa, obtiveram-se os pontos coincidentes $A^{\prime}$ e $B^{\prime}$, com os quais foi possível traçar as semirretas $\overrightarrow{A A^{\prime}}$ e $\overrightarrow{B B^{\prime}}$ com a ferramenta "Semirreta". Estas semirretas foram traçadas considerando-se que os dois vértices restantes do trapézio se localizaram sobre elas.

Para estabelecer a localização exata dos vértices restantes, o ponto centro $C_{1}$ foi inserido entre $A$ e $B$, a partir do qual traçou-se uma reta perpendicular à reta $\overleftrightarrow{A B}$ criada previamente. Sobre a reta perpendicular, inseriu-se um ponto $D_{1}$, cuja distância a $C_{1}$ corresponde à altura do trapézio. A partir do ponto $D_{1}$ criou-se uma reta paralela a $\overleftrightarrow{A B}$, a qual interceptou as semirretas traçadas anteriormente, gerando os vértices restantes do quadrilátero $(C$ e $D)$. Para finalizar, construiu-se o trapézio $A B C D$ com a ferramenta "Polígono", clicando sobre os vértices na sequência $A-B-C-D$ e, novamente, em $A$ para finalizar a figura geométrica (Figura $3)$.

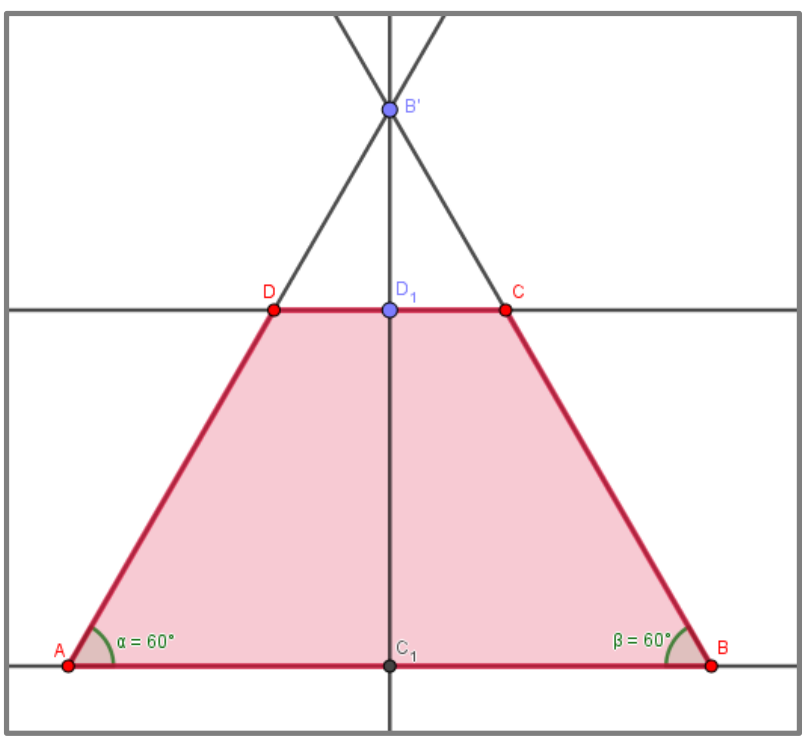

Figura 3. Construção do trapézio isósceles

Fonte: Elaborada pelos autores 


\subsection{Criação da animação}

A animação do recurso está baseada na aplicação de duas transformações geométricas no plano desenvolvidas em três momentos. No primeiro momento, foram extraídos os triângulos $D C B$ e $D C A$ da região poligonal do trapézio mediante uma translação. No segundo momento, o triângulo $D C B$ foi sobreposto ao triângulo $D C A$ por meio de uma rotação aos vértices do primeiro. Por último, ambas transformações foram refeitas com o intuito de voltar ao início da animação, no qual se visualizam as diagonais do trapézio com os símbolos utilizados para indicar congruência entre lados de um polígono.

Para aplicar a translação do primeiro momento, utilizou-se a ferramenta "Translação por um Vetor", a qual requer o objeto que vai ser transladado e o vetor de translação. Nesse sentido, foi construído o triângulo $D C B$ com a ferramenta "Polígono". Para a construção do vetor, tomou-se como sua origem o vértice $D$, sua direção a reta $\overleftrightarrow{D C}$ e seu extremo um ponto móvel sobre o lado $\overleftrightarrow{D C}$. A razão de selecionar, como extremo do vetor, um ponto móvel corresponde à ideia de criar um efeito visual, no qual o usuário observa como o triângulo movimenta-se dinamicamente na região interna do trapézio. Logo, a magnitude " $e$ " do vetor é dada pelo intervalo de valores $0 \leq e \leq i$, no qual o valor " $i$ " é a distância entre os vértices $D$ e $C$. A ferramenta do GeoGebra que permite representar intervalos de valores é chamada de "Controle Deslizante". Ela cria um controle que permite ao usuário realizar a variação dos valores do intervalo desde o valor mínimo ao máximo.

Por essa razão foi criado o controle deslizante com um valor mínimo igual a 0 e um valor máximo igual a $i$, valor este obtido previamente com o uso da ferramenta "Distância, Comprimento ou Perímetro", e clicando em $D$ e $C$. Para estabelecer relação entre o controle deslizante e a localização do extremo do vetor, desenhou-se uma circunferência com a ferramenta "Círculo dados Centro e Raio". $D$ foi o centro da circunferência e o controle deslizante de seu raio. A circunferência obtida foi interceptada com o lado $\overline{D C}$ no ponto $F$, a partir do qual foi desenhado o vetor $\overrightarrow{D F}$. Uma vez obtidos os elementos necessários para aplicar 
a transformação, foi usada a ferramenta "Translação por um Vetor", clicando sobre o triângulo $D C B$ e sobre o vetor $\overrightarrow{D F}$, nessa ordem, gerando assim a translação desejada. Em seguida, aplicou-se uma simetria de reflexão ao triângulo transladado com eixo de simetria à reta $\overleftrightarrow{C_{1} D_{1}}$ desenhada previamente, usando a ferramenta "Reflexão em Relação a uma Reta" para obter o segundo triângulo da divisão do trapézio (Figura 4).

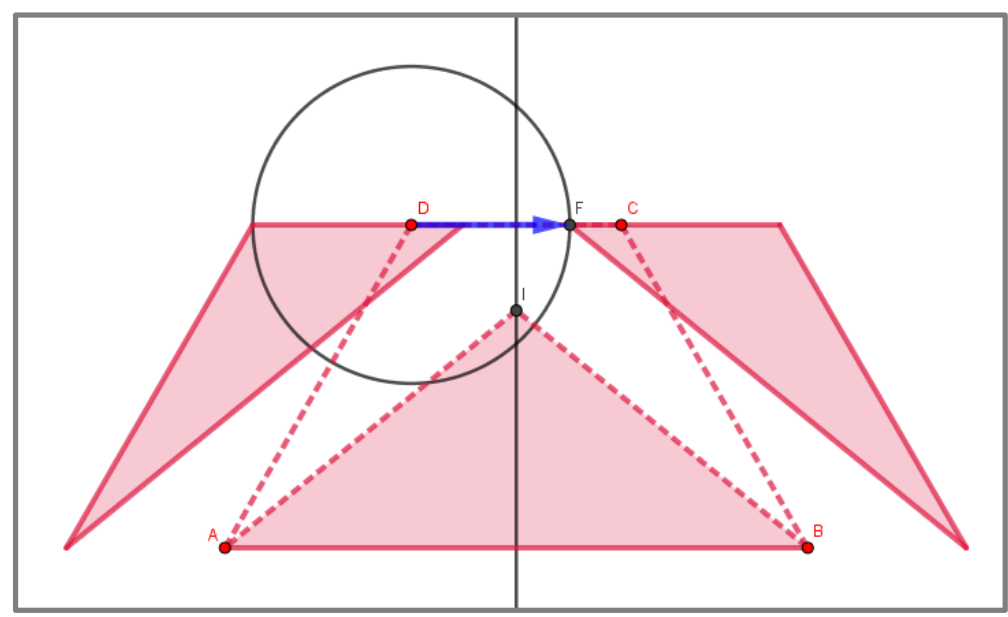

Figura 4. Translação e simetria de reflexão aplicadas ao triângulo $D C B$ Fonte: Elaborada pelos autores

Como indicado no primeiro parágrafo desta subseção, no segundo momento da animação do recurso aplicou-se uma rotação aos vértices $D^{\prime}, C^{\prime}$ e $B^{\prime}{ }_{1}$ do triângulo obtido a partir da translação ao triângulo $D C B$. A ferramenta utilizada para aplicar estas rotações foi "Rotação em Torno de um Ponto", a qual requer a definição do centro e do ângulo de rotação do objeto que vai ser rotacionado. Para as três rotações a serem feitas, decidiu-se usar, como centro da rotação, o ponto $B^{\prime}$. O primeiro vértice rotacionado foi o ponto $D^{\prime}$, o qual precisou ser rotacionado em um ângulo de $60^{\circ}$, já que o ângulo $\angle C_{1} B_{1} D^{\prime}$ formado pelo eixo de simetria do trapézio $\overleftrightarrow{C_{1} B_{1}}$ e a semirreta $\overrightarrow{B_{1} D^{\prime}}$ mede $30^{\circ}$. Essa medida se deve ao fato de o triângulo $C_{1} B^{\prime} B$ ser retângulo, com terceiro ângulo igual a $60^{\circ}$ (Figura 5). 


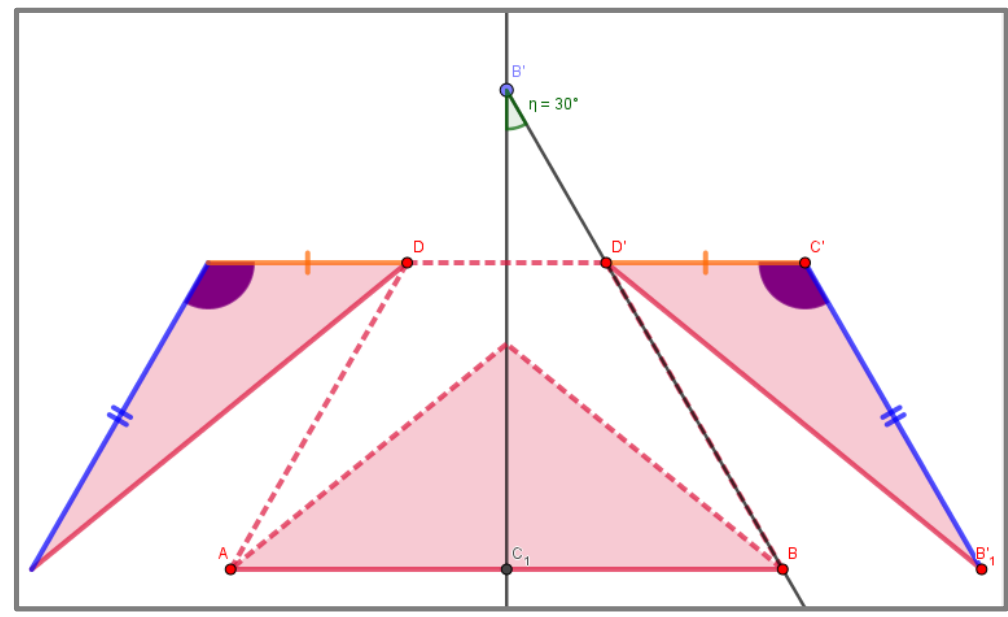

Figura 5. Metade do ângulo de rotação aplicada ao vértice $D^{\prime}$ Fonte: Elaborada pelos autores

Com base na rotação do ponto $D^{\prime}$, na mesma ideia de criar o efeito visual de movimento dinâmico aplicado à translação, construiu-se um controle deslizante $\gamma$ do tipo ângulo com valor mínimo de $0^{\circ}$ e valor máximo de $60^{\circ}$. Desta forma, aplicou-se a rotação usando a ferramenta indicada, clicando nos pontos $D^{\prime}$ e $B_{1}$, nessa ordem, e colocando, como valor do ângulo, o controle deslizante $\gamma$. Isso permitiu obter o primeiro vértice do triângulo rotacionado. Seguindo um procedimento similar, foram obtidos os dois vértices restantes exceto pelo fato de que, para ambas rotações, o ângulo de rotação usado foi colocado em função do controle deslizante. Por exemplo, o vértice $C^{\prime}$ devia ser rotacionado em um ângulo de $120^{\circ}$, pois o ângulo colocado na rotação foi $\theta=2 \cdot \gamma$. Desse modo, a rotação dos três vértices seria desenvolvida usando o mesmo controle deslizante. Após obtenção dos três vértices rotacionados, construiu-se o novo triângulo com a ferramenta "Polígono".

\subsection{Programação da animação}

Por se tratar de um OA, foi necessário inserir certas pausas na animação para permitir ao usuário interagir adequadamente com o recurso. As pausas foram inseridas mediante um conjunto de comandos, isto é, funcionalidades dinâmicas que permitem criar e modificar objetos matemáticos na "Janela de Visualização" do GeoGebra com base em expressões cuja sintaxe é predefinida 
pelo software (CASTILLO; PRIETO, 2018). Assim, esses comandos dizem respeito a ações que se desenvolvem no software, tais como exibir e esconder objetos na tela, mudar atributos de objetos (cor, opacidade, etc.) e iniciar a animação automática de controles deslizantes.

Para realizar a execução dos momentos de translação, rotação e retorno nessa ordem - nos quais se desenvolve a animação elaborada, foi necessário utilizar a ferramenta "Botão" do GeoGebra, a qual permite executar um conjunto de comandos em uma sequência ordenada ${ }^{2}$. Desse modo, os botões "Iniciar", "Continuar" e "Finalizar" foram criados para executar os momentos de translação, rotação e retorno, nomeados anteriormente. As subseções abaixo explicam, separadamente, as formas nas quais foram programados os três botões com o objetivo de atingir a animação final no recurso.

\section{a) Botão "Iniciar"}

O botão "Iniciar" tem a função de começar a animação do recurso, o que significa executar a translação do triângulo $A B C D$ ao clicar diretamente no botão. Dado que essa translação foi realizada a partir do controle deslizante " $e$ ", foi necessário escrever o comando IniciarAnimação[e,true] na janela "Ao Clicar" da seção "Programação" do botão "Iniciar", localizada nas propriedades desse objeto (Figura 6). Para permitir que a animação do controle deslizante " $e$ " fosse interrompida ao chegar a seu valor máximo, colocou-se, na janela "Ao Atualizar" da programação do botão, o comando $S e[e==i$,IniciarAnimação[e,false $]]$, o qual executa a condição de interromper a animação do botão se o controle deslizante alcançar o seu valor máximo "i".

2 Os comandos que são escritos na janela de "Programação" de todo objeto no GeoGebra - como no caso dos botões - recebem o nome de "roteiros". 


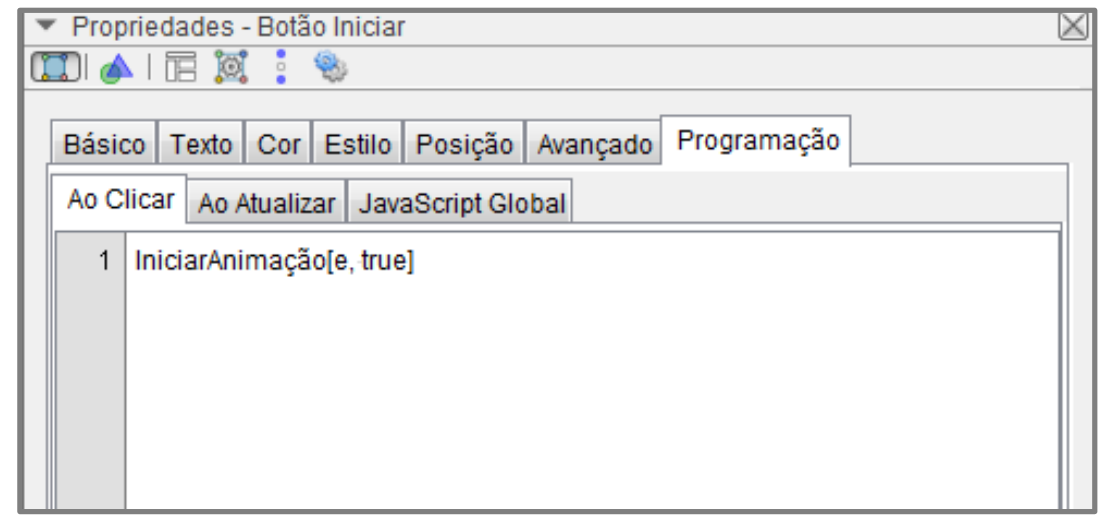

Figura 6. Janela da programação do botão "Iniciar" Fonte: Elaborada pelos autores

Outro aspecto importante da programação deste momento se refere àqueles objetos que são escondidos para dar entrada a outros objetos que se revelarem necessários para a animação. Por exemplo, para criar o efeito visual que mostra como os primeiros triângulos são extraídos da região interna do quadrilátero, o trapézio $A B C D$ e as suas diagonais são escondidos da "Janela de Visualização" do software. Isso ocorre ao clicar no botão "Iniciar" por meio da expressão $e=0$ colocada no campo de entrada "Condição para Exibir Objetos(s)" da seção "Avançado", nas propriedades do quadrilátero. Ou seja, isso significa que os dois objetos somente aparecem na tela quando o controle deslizante estiver em seu valor mínimo (nesse momento, a translação não está em execução). Do mesmo modo, ao clicar no botão "Iniciar" são exibidos os triângulos transladados, assim como o triângulo $A B I$, cuja função é ilustrar o efeito visual daquela parte do trapézio, a qual não foi extraída da sua região poligonal.

Ao longo da animação do recurso é possível observar diferentes objetos, os quais são exibidos e ocultados, tais como os textos que informam as instruções e o conteúdo teórico vinculados à animação ao usuário. Todos esses objetos têm alguma condição que permite sua exibição na tela do computador de acordo com o momento da animação.

\section{b) Botão "Continuar"}


Analogamente ao caso anterior, foi necessário escrever o comando IniciarAnimação $[\gamma$, true $]$ para que a rotação do triângulo $D^{\prime} C^{\prime} B^{\prime}{ }_{1}$ fosse executada ao clicar no botão "Continuar". Esse comando foi inserido na janela "Ao Clicar" nas propriedades do botão, de modo que o controle deslizante $\gamma$ iniciasse a animação automaticamente. Do mesmo modo, escreveu-se o comando $\operatorname{Se}[\gamma==$ $60^{\circ}$, IniciarAnimação $[\gamma$, false $\left.]\right]$ na janela "Ao Atualizar" do botão, para que o controle deslizante interrompesse a sua animação ao alcançar o seu valor máximo.

\section{c) Botão "Finalizar"}

Primeiramente, para retornar completamente a animação ao seu início, foi necessário escrever o comando IniciarAnimação[ $\gamma$, true], na janela "Ao Clicar", das propriedades do botão "Finalizar". Isso permitiu retornar o controle deslizante ao seu valor mínimo. Em consequência disso, o triângulo $D^{\prime} C^{\prime} B^{\prime}{ }_{1}$ retornou à posição que ocupava após a translação. Em segundo lugar, inseriram-se, na janela "Ao Atualizar" de " $\gamma$ ", os comandos $\operatorname{Se}[\gamma==0$, IniciarAnimação $[\gamma$, false $]]$ e $\operatorname{Se}[\gamma==0$, Iniciar Anima ção[e, true $]]$. O primeiro teve o propósito de interromper a animação do controle $\gamma$, ao obter o seu valor mínimo. O segundo comando iniciou a animação do controle " $e$ " no mesmo instante. Por último, escreveu-se o comando $\operatorname{Se}[e==0$, IniciarAnimação[e,false $]]$ na janela "Ao Atualizar" do controle " $e$ " para interromper a sua animação quando o seu valor mínimo fosse alcançado (momento este em que o trapézio aparece completo na tela). A próxima seção resume as reflexões propiciadas por esse artigo.

\section{Considerações finais}

O objetivo deste artigo foi o de descrever a elaboração de um objeto de aprendizagem utilizando o software GeoGebra para favorecer a exploração e a validação de propriedades geométricas estudadas nos Anos Finais do Ensino Fundamental. Logo, discutiu-se a elaboração de um OA envolvendo congruência de triângulos e demonstrações de propriedades de quadriláteros. 
Esse OA foi criado no intuito de contribuir na aprendizagem dos estudantes dos Anos Finais do Ensino Fundamental por meio de processos de exploração, de uso de medidas e da validação de ideias e relações matemáticas. Essas relações oferecem a oportunidade de ampliar possibilidades na demonstração de propriedades de quadriláteros por meio da identificação da congruência de triângulos.

Pensando na ampliação de possibilidades de aprendizagem geométrica do estudante, ficou evidente que o professor que ensina matemática no Ensino Fundamental precisa planejar tarefas que considerem momentos de visualização, investigação e discussão durante o uso do $\mathrm{OA}$ em sala de aula. Enfatiza-se a importância de elaborar tarefas com questões investigativas que levem 0 estudante a explorar e realizar simulações com o OA. Além disso, o professor pode abordar outros aspectos do OA como, por exemplo, as próprias transformações geométricas (rotação, reflexão, translação) usadas na elaboração do objeto.

Do mesmo modo, pode-se pensar na aprendizagem do professor que ensina matemática enquanto ele interage com o próprio OA. Essa interação pode acontecer tanto no momento em que ele explora as ideias e as relações matemáticas do próprio OA como no momento em que ele elabora esse tipo de recurso.

O professor que ensina matemática pode elaborar os seus próprios $\mathrm{OA}$, ao se apropriar de conhecimentos matemáticos (ideias, relações, propriedades, conceitos) instrumentais (ferramentas do software, comandos, linguagem de programação) e didáticos (tarefas, natureza do OA). Nesse sentido, indica-se a necessidade de oferecer aos professores da Educação Básica processos de formação continuada sobre a utilização de OA para o ensino de geometria. 


\section{Referências}

AUDINO, D. F.; NASCIMENTO, R. S. Objetos de aprendizagem: diálogos entre conceitos e uma nova proposição aplicada a educação. Revista Contemporânea de Educação, Rio de Janeiro, v. 5, n. 10, p.128-148, 2010.

BRASIL. Ministério da Educação. Base Nacional Curricular Comum - BNCC (Ensino Fundamental). Brasília, 2017.

CASTILLO, L. A.; PRIETO, J. L. El uso de comandos y guiones en la elaboración de simuladores con GeoGebra. UNIÓN, Revista Iberoamericana de Educación Matemática, Madri, n. 52, p.250-262, 2018.

GALLO, P.; PINTO, M. G. Professor, esse é o objeto virtual de aprendizagem. Revista Tecnologias na Educação, São Luís, n. 1, p. 1-12, 2010.

HANNA, G. Proof, explanation and exploration: an overview. Educational Studies in Mathematics, Zurique, n.44, p.5-23, 2000.

HOHENWARTER, J.; HOHENWARTER, M.; LAVICZA, Z. Introducing dynamic mathematics software to secondary school teachers: The case of GeoGebra. Journal of Computers in Mathematics and Science Teaching, Waynesville, v. 28, n. 2, p. 135146, 2009.

HOYLES, C.; JONES, K. Proof in Dynamic Geometry Contexts. In: MAMMANA, C.; VILLANI, V. (Org.). Perspectives on the Teaching of Geometry for the 21st Century. Dordrecht: Kluwer, 1998.

KALINKE, M. A.; DEROSSI, B.; JANEGITZ, L. E.; RIBEIRO, M. S. N. Tecnologias e educação matemática: um enfoque em lousas digitais e objetos de aprendizagem. In: KALINKE, M. A.; MOCROSKY, L. F. (Org.). Educação matemática: pesquisas e possibilidades. Curitiba: Ed. UTFPR, 2015.

KOPER, R. Combining re-usable learning resources to pedagogical purposeful units of learning. In: LITTLEJOHN, A. (Org.). Reusing online resources: a sustainable approach to eLearning. Londres: Kogan Page, 2003.

NACARATO, A. M.; GOMES, A. A. M.; GRANDO, R.C. Grupo colaborativo em Geometria: uma trajetória...uma produção coletiva. In: NACARATO, A. M.; GOMES, A.M; GRANDO, R. (Org.) Experiências com Geometria na Escola Básica: narrativas de professores em (trans) formação. São Carlos: Pedro \& João Editores, 2008.

OLIVERO, F.; ROBUTTI, O. Measuring in dynamic geometry environments as a tool for conjecturing and proving. International Journal of Computers for Mathematical Learning, n. 12, p.135-156, 2007.

POWELL, A. Construção Colaborativa do Conhecimento Tecnológico, Pedagógico e do Conteúdo de Professores de Matemática. Boletim Gepem, Seropédica, n.63, p. 1-15, 2014. 
SABBATINI, M. Reflexões críticas sobre o conceito de objeto de aprendizagem aplicado ao ensino de ciências e matemática. EM TEIA - Revista de Educação Matemática e Tecnológica Iberoamericana, Recife, v. 3, n. 3, p. 1-36, 2012.

SANTOS, M. E. K. L. Objetos e ambientes virtuais de aprendizagem no ensino de matemática: um estudo de caso para o estágio supervisionado de docência. Dissertação de mestrado - Universidade Cruzeiro do Sul, São Paulo, 2007.

SCHER, D. Square or not? Assessing constructions in an interactive geometry software environment. In: MASALKI, W.J.; ELLIOT, P. C. (Org.) Technology-supported mathematics learning environments. 67 ed. Nova lorque: NCTM, 2005.

SINCLAIR, N.; YURITA, V. To be or to become: how dynamic geometry changes discourse. Research in Mathematics Education, Londres, v.10, n.2, p. 1-30, 2008.

STYLIANIDES, G. J.; STYLIANIDES, A. J. Validation of solutions of construction problems in dynamic geometry environments. International Journal of Computers for Mathematical Learning, Waynesville, n.10, p. 31-47, 2005. 